\title{
5 Erratum für: iit-Themenband, DIGITALISIERUNG, Bildung/Technik/Innovation
}

(Hrsg.) Volker Wittpahl

Trotz sorgfältiger Erstellung unserer Bücher lassen sich Fehler nie ganz vermeiden. Daher möchten wir auf Folgendes hinweisen:

Auf S. 59, S. 117 und S. 191 wurde versehentlich ein falscher Hinweistext für Open Access eingefügt; den korrekten Text finden sie nachfolgend, die entsprechenden Originalpassagen wurden entsprechend geändert.

Open Access Dieses Kapitel wird unter der Creative Commons Namensnennung 4.0 International Lizenz (http://creativecommons.org/licenses/by/4.0/deed.de) veröffentlicht, welche die Nutzung, Vervielfältigung, Bearbeitung, Verbreitung und Wiedergabe in jeglichem Medium und Format erlaubt, sofern Sie den/die ursprünglichen Autor(en) und die Quelle ordnungsgemäß nennen, einen Link zur Creative Commons Lizenz beifügen und angeben, ob Änderungen vorgenommen wurden.

Die in diesem Kapitel enthaltenen Bilder und sonstiges Drittmaterial unterliegen ebenfalls der genannten Creative Commons Lizenz, sofern sich aus der Abbildungslegende nichts anderes ergibt. Sofern das betreffende Material nicht unter der genannten Creative Commons Lizenz steht und die betreffende Handlung nicht nach gesetzlichen Vorschriften erlaubt ist, ist für die oben aufgeführten Weiterverwendungen des Materials die Einwilligung des jeweiligen Rechteinhabers einzuholen.

Die aktualisierte Originalversion dieses Titels ist verfügbar unter:

DOI 10.1007/978-3-662-52854-9

V. Wittpahl (Hrsg.) Digitalisierung,,

DOI 10.1007/978-3-662-52854-9_4, C Der/die Autor(en) 2017 